Social Work/M aatskaplike Werk Vol 51 No 1; Issue 1

http://socialwork.journals.ac.za/pub

doi:http://dx.doi.org/51-1-425

HOMELESSNESS AND MENTAL ILLNESS IN HILLBROW, SOUTH AFRICA: A SITUATION ANALYSIS

Ms Unotida Moyo, MA student; Prof Leila Patel, Director of the Centre for Social Development in Africa (CSDA); Prof Eleanor Ross, Visiting Professor at the CSDA, University of Johannesburg, Johannesburg, South Africa.

Abstract

This study explored the social situation of homeless people with mental illness living on the streets of Hillbrow, Johannesburg, with the view to facilitating action in terms of support services. Data were collected via interviews and observations from three groups: homeless persons with suspected mental illness, homeless people and service providers. The research focused on reasons for homelessness; health and living conditions; relationships between homeless persons and those with mental illness; survival strategies; and services utilised. Results were presented to all stakeholders and a forum was established to enable the findings to be taken forward. 


\section{HOMELESSNESS AND MENTAL ILLNESS IN HILLBROW, SOUTH AFRICA: A SITUATION ANALYSIS}

\section{Unotida Moyo, Leila Patel, Eleanor Ross}

\section{INTRODUCTION}

While there has been substantial research into the phenomenon of homelessness in South Africa (Cross, Seager, Erasmus, Ward \& Donovan, 2010; Malindi, 2014; Mathiti, 2006; Mathebula \& Ross, 2013; Olufemi, 1998; Sewpaul, Osthus, Mhone, Sibilo \& Mbhele, 2012), the issue of homeless persons with mental illness has received limited attention from researchers, service providers, policy makers and local authorities, and very little is known about this group of persons (Ross, 2014). Seager and Tamasane (2010:72) estimate that $6 \%$ of adults with severe chronic psychiatric illnesses are homeless, although this figure is thought to be increasing.

Homeless persons living on the streets find themselves in conditions that are likely to produce and aggravate symptoms of mental illness (Ambrosino, Ambrosino, Emeritus \& Emeritus, 2008). The nature of mental illness also makes it "difficult for homeless persons to negotiate street life and meet basic needs for food, safety, shelter and treatment” (Ambrosino et al., 2008:223) and they may experience ill health as a result of respiratory infections, dermatological problems, as well as risk of exposure to HIV and Tuberculosis (Ambrosino et al., 2008). Moreover, despite the existence of progressive social policies and legislation, the rights of many homeless and homeless mentally ill persons are violated as implementation in mental health lags behind policy and legislation (Freeman, 2013).

For these reasons a master's-level study was undertaken under the auspices of the Department of Social Work and the Centre for Social Development in Africa (CSDA) at the University of Johannesburg. The lived experiences of homeless persons and those with mental illness living on the streets in the urban context of Hillbrow, Johannesburg was documented with a view to understanding their situation and taking action to facilitate support services. Objectives included ascertaining (i) the living conditions and vulnerability to health and other social problems of homeless persons with suspected mental illness living on the streets of Hillbrow; (ii) the survival strategies they employed; (iii) reasons for their being homeless; (iv) their relations with other homeless people in the groups where they sleep; (v) the services they utilise and their perspectives on these services; and (vi) strategies for overcoming homelessness.

In line with a commitment to involving the community in the project, a workshop was subsequently held with all stakeholders in Hillbrow, including homeless persons, homeless persons with suspected mental illness and service providers. The workshop provided an opportunity for them to evaluate and critically reflect on the results and engage in action to take forward the initiative. To this end, this article discusses the research and the decisions taken at the workshop. 


\section{LITERATURE REVIEW}

\section{Homelessness in South Africa}

While homelessness is a worldwide problem, persons with mental illness are overrepresented among the homeless relative to the general population, and mental illness is one of a myriad of vulnerabilities likely to confer risk of homelessness (Sullivan, Burnam \& Koegel, 2000). In South Africa homelessness is identified by Cross et al. (2010:130) in terms of three types, namely, "the detached homeless, temporary overnight sleepers and informal settlement dwellers, of which the first two are referred to collectively as street homeless persons".

From a historical perspective, homelessness in South Africa is inextricably linked with the lingering colonial and apartheid legacies of migrant labour, controlled urbanisation policies and the creation of racially segregated residential areas that resulted in huge housing backlogs. Despite the dismantling of apartheid and the government's efforts to address land and housing issues, homelessness continues to be a problem. According to Cross et al. (2010), the seriousness of homelessness in South Africa is overshadowed by the extent of the population residing in shack dwellings. Given the lack of a fixed address and the mobility of shack dwellers, there would appear to be an undercount of this population. Kok, Cross and Roux (2010) found that the street homeless population was young, made up of older children and single, working-age adults, and was predominantly male and black.

\section{Homelessness and mental illness}

According to the Diagnostic and Statistical Manual of Mental Disorders (DSM-5, 2013),

a mental disorder is a syndrome characterized by clinically significant disturbance in an individual's cognition, emotion, regulation, or behaviour that reflects a dysfunction in the psychological, biological, or developmental processes underlying mental functioning. Mental disorders are usually associated with significant distress in social, occupational, or other important activities (American Psychiatric Association, 2013: n.p.).

Research has shown that homelessness and mental illness are interdependent variables in that one can cause the other and vice versa. Some scholars contend that mental illness itself contributes to homelessness as the person's mental illness impairs his or her ability to function (Ambrosino et al., 2008). Family breakdown, depression as well as economic and material deprivation also give rise to homeless mentally ill persons, because they become materially, socially and emotionally drained of resources (McNaughton, 2008). However, Sullivan et al. (2000:444) contend that "mental illness may play a role in initiating homelessness for some, but is unlikely in and of itself to be a sufficient risk factor for homelessness". Nevertheless, some homeless people become mentally ill when they are already on the streets, which can be attributed to the conditions and stresses to which they are exposed and the associated stigma. Substance abuse is also regarded as a reason for homeless persons becoming mentally ill (Sullivan et al., 2000) or a consequence of time spent on the streets (Christensen, 2014). 


\section{Factors contributing to the phenomenon of homeless persons with mental illness}

Previously many people who were diagnosed with severe mental illness were confined in psychiatric hospitals or similar institutions. However, in the mid-1950s deinstitutionalisation became a major determinant of mental health policy internationally whereby mentally ill persons were returned to families and communities without the necessary supportive services. Although deinstitutionalisation was not a cause of homelessness in itself, it has been identified as a risk factor for homelessness (Carol, Karina, David \& Edward, 2004). Moreover, mental illness among homeless persons may be exacerbated by life on the streets (Cross et al., 2010).

Many homeless youths leave home after years of physical and sexual abuse, strained relationships, addiction of a family member and parental neglect (Ambrosino et al., 2008). The premature deaths of parents through AIDS and other factors, with the resultant increase in child-headed households, have also increased the risk of homelessness for many children.

Markos, Baron and Allen (2005) contend that the primary causes of homelessness are poverty and unemployment, which are exacerbated by the high cost of living and additional costs involved in working, such as transport to and from work (Cross et al., 2010:10). The economic meltdown in Europe and the Americas further exacerbated the problem in South Africa. According to Tipple and Speak (2009), many households cannot afford a dwelling of any sort and have to share housing or build informal dwellings in rural and urban areas on land they do not own. The public housing backlog in South Africa is still huge, despite accelerated housing delivery in the past few years. Furthermore, an extensive waiting list for public housing means that families must remain in shelters, inadequate housing arrangements or on the streets (Ambrosino et al., 2008). A lack of adequate low-cost subsidised housing severely affects the homeless mentally ill population (Garvin, 1998).

Substance abuse has also been highlighted as a reason for many people becoming homeless. Studies in both the UK and US concur that approximately one third of people who live on the streets experience significant and on-going problems with alcohol and other drugs (Koegel \& Burman, 1988 as cited in Power \& Attenborough 2003:43; Scott, 1993). Similar findings on the relationship between homelessness and drug abuse were noted by the South African researcher, Mathiti (2006).

\section{Mental health policies and services for homeless people in South Africa}

The South African Mental Health Care Act No 17 of 2002 upholds the rights of persons with mental illness to be protected from discrimination and to receive care and services in the communities where they reside. The Disability Rights Charter of South Africa (2008) and the Bill of Rights of the Constitution of the Republic of South Africa (1996) also protect the rights of everyone to basic health care services, sufficient food and water, adequate housing, social security and social services. Nevertheless, there is often a disjuncture between policies and implementation of service delivery (Freeman, 2013). 
In South Africa the public/government hospitals are the health care institutions most commonly used by homeless persons. Mathiti (2006) maintains that lack of access to service provision for homeless persons with mental illness is often related to the unwillingness of health care professionals to treat homeless people as they tend to perceive them as dirty. For example, a study in South Africa conducted by Zrinyi and Balogh (2004, cited in Mathiti, 2006) showed that student nurses would decline to care for homeless people in various situations. This reaction was the result of the way the homeless body has been stereotyped as unworthy and undeserving of medical services. Mathiti (2006:218) asserts that "the inaccessibility of health care services is a key issue in understanding the high mortality rate among homeless people”. The failure of homeless persons with mental illness to provide an address and to keep appointments, because of their mobility, serves as a further alienating factor.

In South Africa social welfare and community mental health services for homeless persons are delivered largely by NGOs and faith-based organisations that may receive some level of government funding support. There have been many challenges in welfare service delivery as a result of the under-funding of these services by national and provincial governments (Patel, Hochfeld, Graham \& Selipsky, 2008). Soup kitchens, cafes and drop-ins also operate to provide food and facilities for people on the margins. Often these drop-in services are not funded through the government system, but through faith-based organisations (McNaughton, 2008). However, most of these organisations tend to deal with the problem of homelessness instead of its causal factors.

Against this backdrop, the study was framed by the human rights approach, which focuses on the rights of homeless and homeless mentally ill persons, and the ecological perspective, which seeks to understand homeless persons with mental illness in terms of their relationships with other homeless persons, service providers and the broader society.

\section{METHODOLOGY}

The research took the form of a qualitative study followed by a feedback workshop for all stakeholders. Babbie (2013:390) defines qualitative analysis as "the nonnumerical examination and interpretation of observations, for the purpose of discovering underlying meanings and patterns of relationships". The research was of an exploratory nature and provided valuable insights into the complexities of conducting research with homeless persons, particularly those with mental illness. The setting for the study was Hillbrow, which is a high-density area situated 3.5 kilometres from the central business district of Johannesburg and is home to a highly mobile cosmopolitan population of migrants from various African countries and persons from rural areas. Three data sources were utilised, namely (i) six service providers, that is, three from the Hillbrow Community Health Centre run by the City of Johannesburg (commonly known as Hillbrow clinic), two from the Methodist Evangelical Services (MES) and one from the Twilight Children outreach project; (ii) six homeless persons; and (iii) six homeless persons with suspected mental illness. 
Purposive sampling via a standardised diagnostic tool was used to identify the homeless and the homeless mentally ill persons. The sample size was restricted to 18 participants as it was difficult to recruit a larger sample of homeless persons with suspected mental illness in view of their lack of trust of others, their general levels of confusion and the fact that the sleeping sites of homeless people are generally perceived to be dangerous. Snowball sampling was used whereby homeless persons referred the researcher to other sites where mentally ill homeless persons resided. This was done until saturation was reached. In order to minimise these limitations, potential respondents were approached cautiously by the first author, who is a social worker in Hillbrow, and efforts were made to slowly build a rapport with them.

Three interview schedules were developed, namely, one for the homeless persons with suspected mental illness; one for the homeless persons; and one for service providers. The schedules were designed to establish a holistic understanding of the lived experiences of the homeless persons with suspected mental illness in terms of reasons for homelessness, their living conditions on the streets, how they related with other homeless persons, survival strategies, services utilised, and recommendations for addressing homelessness.

In addition to the interview schedules, a standardised diagnostic instrument was used which is made up of two parts, namely the Mental Status Examination (MSE) and the Mini Mental State Examination (MMSE). On the advice of a psychiatrist from the Hillbrow Psychiatric Clinic, this tool was used to identify the homeless mentally ill persons on the streets of Hillbrow. However, although the tool has eight parts, only those parts which could be used by mental health social workers were utilised, namely: (i) History, which encompasses the demographic data, history of present illnesses, past psychiatric history, mood symptoms; and (ii) Mental Status Examination (MSE), which includes the overview of the client in terms of general appearance, motor behaviour, attitude to the examiner, level of consciousness, speech and language.

The first part of the tool, the Mental Status Examination (MSE) worked very well for the researcher in terms of identifying persons suspected of experiencing symptoms of mental illness through non-participant observations. However, a limitation of the study is that a diagnosis of mental illness was only confirmed by a psychiatrist in the case of persons who attended the Hillbrow Psychiatric Clinic. A further limitation is that not all persons who participated in the study were willing to undergo the MMSE interview evaluations. Psychiatric assessment may be complicated by the fact that observable symptoms which may be temporary responses to the various stresses to which homeless individuals, or that are adaptations to a homeless existence, are exposed. Moreover, problems involved in administering the standardised diagnostic tool, coupled with the fact that the researcher was a social worker rather than a trained psychiatrist or psychologist, limited the effectiveness of the screening of homeless persons for mental illness. Hence, in the absence of confirmed diagnoses from professionals registered with the Health Professions Council of South Africa (HPCSA), results in respect of the homeless mentally ill sample need to be interpreted with caution. In fact, this sub-sample can only be assumed to have, or be suspected of having, a mental illness. 
A pre-test of the research tools was conducted with three participants, namely a service provider, a homeless person and a homeless person with suspected mental illness. Amendments suggested by participants were incorporated into the final versions of the research tools.

The researcher conducted non-participant observations of the respondents in the morning at their different sleeping sites and also during soup kitchens, and recorded their behaviour and actions. In addition, semi-structured interviews were conducted with 16 respondents comprised of three groups, namely six representatives of organisations providing services in the Hillbrow area that are most frequently utilised by the homeless population, six homeless persons, and four homeless persons with suspected mental illness. With two persons only observations were conducted.

Responses were analysed using thematic content analysis, which Braun and Clarke (2006:79) define as a method for identifying, analysing and reporting themes within data. In analysing the data, the following steps were implemented as conceptualised in Braun and Clarke's (2006) six-stage model: (i) Familiarisation of the researcher with the data; (ii) Initial creation of codes; (iii) Searching for themes; (iv) Reviewing themes; (v) Defining and naming themes; and (vi) Producing a report. In order to enhance the trustworthiness of the data analysis, the following constructs were taken into consideration: credibility was enhanced through pre-testing of the interview schedules, repeated observations and prolonged engagement with participants. In terms of transferability, a detailed description of the purpose and objectives, methodology and findings of the study was provided and triangulation of data sources and methods was employed. Nevertheless, the small, non-probability purposive sample limited transferability of the findings to the broader population of homeless persons. Dependability in this study was enhanced by having the same researcher conduct all the interviews. In relation to confirmability, correspondence checking was employed whereby the researcher's supervisors (the second and third authors) checked and confirmed the categorisation of themes for correspondence.

The following ethical principles were taken into consideration: avoidance of harm, privacy and confidentiality, voluntary participation, the right to withdraw from the study at any time without negative consequences, and informed consent (Ivanoff \& Blythe, 2011). For the homeless persons with suspected mental illness, permission at family and individual level (to some extent) could not be sought as some were out of touch with reality and were unable to provide details of their next-of-kin. However, with those homeless persons with mental illness who regularly attended Hillbrow Clinic for treatment, permission to approach potential participants was sought from the senior psychiatric nurse. Consent forms were signed by all participants who had the capacity to give informed consent, and were willing to participate in the study and have the interviews audio recorded. Ethical clearance for the study was obtained from the University of Johannesburg Humanities Ethics committee. 


\section{RESULTS AND DISCUSSION}

\section{Profile of homeless persons with suspected mental illness}

A total of four respondents were interviewed consisting of three males and one female. The other two male respondents were not interviewed, because they presented with serious cognitive disturbances, were out of touch with reality, and unaware of where they were going and where they had been. In view of this problem among mentally ill persons, Ambrosino et al. (2008) encourage researchers to conduct and record their actions and behaviour through the use of observation techniques. In this study the first author also used a standardised diagnostic tool to assess participants' mental condition. Other homeless persons reported that one respondent who appeared to be in his early twenties had been experiencing symptoms of mental illness ever since he arrived on the streets; however, his diagnosis was not known. Among the four respondents who were interviewed, three had spouses/partners and the remaining one had no spouse/partner. For the two respondents who were observed, it was difficult to ascertain whether or not they had partners. The respondents had lived on the streets for extended periods, but were unable to give more precise details. All respondents indicated that they had moved to different locations many times, although they were not sure of the exact number of times.

\section{Profile of homeless persons}

A sub-set of six homeless persons living alongside the homeless persons with suspected mental illness was also interviewed. There were more black men in the sub-sample who were homeless than women, namely five black males to one black woman. These findings were similar to those that emerged from a study conducted by Olufemi (1998:230) in Johannesburg, who found that black men living on the streets of Hillbrow outnumbered the women living on the streets in terms of prevalence. The age of respondents ranged from 20 to 30 years with an average of 26 years. Two achieved a Grade 12 qualification while living in a shelter, one respondent had Grade 9 and the rest were either exposed to some training at the shelters or had no schooling at all. They had all moved many times from one location to the other, which is consistent with Ward, Seager and Tamasane's (2010) finding that homeless persons are highly mobile.

\section{Profile of service providers}

From the three organisations approached, six respondents were interviewed. Although three respondents were from the same organisation, two respondents dealt specifically with homeless chronically mentally ill persons, while another respondent, a social worker, dealt with homeless persons in general. Two respondents were from Methodist Evangelical Services (MES), which specialised in the provision of accommodation, and social and spiritual services to the homeless population of adults aged 18 years and older. The last respondent was from Twilight Children and dealt specifically with homeless adults and youths via an outreach project. From the sub-sample of six service providers, four respondents were males and two respondents were females, and five respondents were black and one was white. Respondents included two professional 
nurses, a social worker, two outreach project co-ordinators and a needs assessment manager.

Analysis of the responses revealed six themes, with each containing various sub-themes.

\section{Theme 1: Living conditions and vulnerability to health and other social problems}

Themes that emerged from the analysis of the responses included exposure to crime and violence, and poor health conditions.

\section{Exposure to crime and violence}

The four homeless persons with suspected mental illness who were interviewed all acknowledged that life on the streets was not good; however, they were used to this environment and it had become difficult for them to leave the streets. Three respondents with unconfirmed diagnoses by a psychiatrist indicated that they had been stabbed at some point when they were fighting with other homeless persons. This theme was starkly reflected in comments such as: "That guy beat me up and I developed heart disease. The third time I was beaten up on my knees and were painful as you can see the scars", and "There is no life here, we stab one another, we kill one another and the SAPS [South African Police Service] they arrest us all the time”.

All the homeless respondents indicated that they had been stabbed at some point in their lives on the streets of Hillbrow. The main reason for fighting was over money. One respondent said, "Yah my sister, life is dangerous on the streets, you see this scar, I got it here. My friends have died because we kill each other here and some are shot dead. We live a difficult life because we have seen a lot of dead people especially on Fridays; it no longer affects us like any other person". One person indicated, "In 2010 I was imprisoned for three months after a lady claimed that I wanted to rob her, while I didn't, I just bumped on her in a blind corner and she fell down. Unfortunately the police officers were passing by. Then they arrested me as a robber". These findings were in line with those of Tipple and Speak (2009:93) and Sewpaul et al. (2012:241), who found that homeless persons highlighted the violence and intimidation inflicted on them by police officers.

Homeless female respondents tended to be vulnerable to sexual abuse and rape, as indicated by the verbatim response: "When I arrived here for the first time, I stayed with this guy who raped me and I reported him to the police and he was jailed for three months".

\section{Poor health conditions}

All the respondents in both the group with suspected mental illness and homeless group were coughing and they indicated that they had been coughing for more than three months. When they were asked if they had undergone any medical tests, all responded they had not. All three male respondents among the sub-group of homeless persons with suspected mental illness were not sure of the illnesses they were suffering from. One respondent commented, "I don't know since I am getting thin like this my sister, maybe it's the drugs I used to take". 
Only the homeless female respondent confided to the researcher that she was HIV positive; however, she did not take her medication. In line with these findings, Lister (2003) explains that compliance with treatment and advice is also difficult in an environment where medication can be stolen, where there is nowhere to rest and keep warm, and when general diet and nutrition are poor. One service provider commented, "We used to go out on the streets to their hotspots and ask their friends. Sometimes we could find out that they are sick with HIV/AIDS. They could not move anywhere and we called an ambulance for them, or we called the hospices around and we took them there". Another respondent from among the service providers reflected, "They are vulnerable, looking at the fact that they have no place to stay and they have mental illness. It is inhuman for them to be on the streets in their condition".

Lister (2003) and O'Flaherty (2005) provide support for the findings from the respondents that homeless people are at risk of health problems such as tuberculosis, HIV/AIDS and severe upper-respiratory infections, because they are exposed to a range of factors that are associated with poor health such as overcrowded, cold, damp and unsanitary conditions.

\section{Theme 2: Survival strategies for the homeless and homeless persons with suspected mental illness}

Survival strategies that respondents engaged in included economic activities, substance abuse, relationships with partners, compliance with treatment and medication, and reliance on spiritual beliefs.

\section{Economic activities}

One respondent survived on a monthly disability grant as explained in the following response: "I don't want people who will take away my grant and put me in a place (residential care)". Others engaged in economic activities on the streets from which they earned money, for example, "I ask money from people, help with parking of people's cars and I also go and eat at Twilight (a shelter for homeless people) at 2 pm everyday".

The impression gained was that homeless persons negotiated life on the streets just like the homeless persons with suspected mental illness. However, those with suspected mental illness appeared to be more vulnerable, as reflected in the comment from a homeless person: "It is difficult for the homeless mentally ill persons to survive on the streets because they can't even help out with parking. They do nothing all day". Compared to the homeless mentally ill persons, some homeless persons at some point had been involved in casual jobs, as indicated by the following comments: "I park people's cars; I work as a messenger in that Salon down there. They trust me, sometimes they ask me to go and bank their money. I also help out at the locksmith shop". Another respondent said, "I help with electrical work; I fix plugs and switches, for instance. I also help individuals to park their cars ... I wash people's cars. I also help carry other people's luggage". These findings were consistent with those documented by Kok et al. (2010:29), who indicated indicate that homeless persons are often involved in economic activities on behalf of others in order to survive. 


\section{Substance abuse}

All of the six homeless respondents who were interviewed admitted smoking cigarettes and drinking alcohol; however, five respondents denied sniffing glue, even though the researcher had observed them engaged in this practice. One person indicated, "I drink alcohol and I smoke cigarettes, by so doing I don't stress".

Of the four homeless mentally ill respondents who were interviewed, two indicated that they drank alcohol and smoked cigarettes or sniffed glue because of the stresses to which they were exposed on the streets. One respondent said, "Smoking has really disturbed me a lot (referring to glue)". Another one said, "Yes cigarettes, I stopped inhaling glue when I was 13 years, but dagga (marijuana) I do smoke". He added, "For fun, yes for good life time, sometimes if I have extra money I buy myself alcohol to enjoy myself". In line with these findings, Cohen (2001) maintains that the use of drugs and alcohol is one method by which individuals deal with the lack of activities in their lives.

\section{Compliance with treatment and medication}

Besides the two above survival strategies, compliance with medication was perceived to be a survival strategy for the diagnosed homeless mentally ill persons. This strategy was witnessed in one respondent who had been on the streets for 30 years and had been undergoing psychiatric treatment for 20 years. When the service providers were asked how they monitored those in their treatment programmes, they indicated that all their homeless patients collected their medication once a week as indicated by the response, "The only assurance we have is that they have never showed any signs of relapsing, so in other words they are compliant and they have never missed their appointments". A surprising finding was a couple who had stayed on the streets of Hillbrow for 30 years and had been on treatment for 20 years and still followed their treatment diligently. A homeless person also survived by being compliant with her anti-retroviral treatment. When she was asked how often she visited the clinic, she indicated, "only when I am sick or for my treatment for HIV/AIDS”.

\section{Relationships with partners}

It was also noticed that two of the respondents who had partners appeared to survive far better than those who were loners, possibly because of the support they received from their partners. This support was shown by one respondent, who indicated that her boyfriend gave her money to survive.

\section{Spiritual beliefs}

One homeless respondent said, "I survive because I go to church, I believe in God even now I have my Bible in this bag of mine".

It is of interest that none of the respondents mentioned the use of sexual activities as a survival strategy. According to Ambrosino et al. (2008), in order to survive on the streets, homeless persons often find themselves exchanging sex for food, clothing and shelter, thereby putting themselves at risk of contracting HIV/AIDS and other sexually transmitted infections. 


\section{Theme 3: Reasons for being homeless}

Findings are discussed separately for each of the three groups.

\section{The homeless persons with suspected mental illness}

Of the various push and pull factors mentioned, the most frequent reason for homelessness was family breakdown. Participants were asked about the whereabouts of their parents and siblings and the length of time since they had last seen their relatives. Three respondents indicated that their parents had passed on and three had never known them. One of the respondents stated that he only had a father and his mother had passed away a long time ago. As a result of lack of family support because of parents not being there for them, they landed up on the streets. It emerged that all the homeless persons with assumed mental illness were from broken families. According to May, Page and Brunsdon (2001:123), surveys have consistently shown that "the family backgrounds of many homeless people have been characterised by conflict and abuse, and severe family conflict often causes homeless people to leave home whether by choice or by coercion”. In a similar vein, Tipple and Speak (2009:75) state that lack of ability to maintain relationships and friendships is one of the disturbing expressions of homeless persons with mental illness.

Only one respondent acknowledged the use of substances to have elicited some symptoms of mental illness in his life, as reflected in the comment, "You know drugs are destroying us, sometimes you see yourself acting in a strange way, but it does not mean that I am mad, no my sister I am not”. Other homeless persons and service providers also indicated support for this theme. For example, a homeless person said, "We know him from long ago before he became mad. He was hurt at his heart here on the streets and on the other side of the head". A service provider stated, "I think some become mentally ill by staying on the streets for quite a long time".

From the respondents who were both interviewed and observed, it emerged that four of them did not know how they landed up on the streets. One respondent indicated, "I ran away from school". However, earlier in the interview she had indicated that she came to the streets after she had completed Grade 12. This statement suggests that she was confused about how she landed on the streets.

\section{The homeless persons}

Five out of the six homeless respondents gave similar reasons for being on the streets of Hillbrow, including family breakdown, seeking employment, seeking adventure or independence, and engaging in criminal activities. One respondent seemed to have no apparent reason.

\section{The service providers}

The respondents were asked whether at some point both the homeless persons with mental illness and the homeless persons had informed them of their reasons for being on the streets. They reported that their clients do tell them the reasons, even though they are not compelled to disclose private information and also that the reasons differed with individuals. 
In terms of the employment theme, one respondent said, "Sometimes they would have lost their jobs, having been retrenched". Another one stated, "Some they come from rural areas and they come to search for better opportunities, hence at the end of the day they end up on the streets". A further respondent explained, "Others in cases of child trafficking, especially from Zimbabwe, Angola and Mozambique, they take them and promise them they're going to get a job and they then throw them in the farms; hence they tend to run away because they cannot do the job". Closely related to unemployment was the issue of poverty. One respondent indicated, "Some they run away because of poverty". In this respect Mathiti (2006:218) points out that "chronic poverty has become an endemic feature of the landscape of homelessness".

A further factor perceived to contribute to homelessness was family breakdown. One respondent reflected, "Most of them on the streets come from broken families". Another one commented, "Others at the present moment, they are running away from childheaded families. The parents have passed on due to HIVIAIDS and they have to look after their siblings and stop going to school. The challenge becomes so much and they end up running away".

Another person mentioned the issue of seeking adventure and/or independence. She stated that "Some have both parents but they choose to be on the streets. Some they say they needed freedom, to be their own bosses of their lives. Some they come from well-off families ... Some they come for fun in Johannesburg".

Peer pressure also emerged as a contributing factor. As one respondent commented, "Most of them, especially young ones, it is peer pressure; they call each other to go to the city of glamour and lights". One respondent highlighted substance abuse as a causal factor in homelessness. "Alcohol and drugs access, especially in Hillbrow, because they get them at their door steps without walking a distance".

A further theme focused on criminal activities. One respondent said, "They run away from homes because of crimes, which they have performed in their areas. Hence they know when they are here it is difficult to trace them because they don't have any identities, they change their names". Shlay and Rossi (1992) alluded to this finding by revealing that a significant number of homeless persons have criminal histories.

\section{Theme 4: Relationships of homeless persons with suspected mental illness and other homeless persons}

Three respondents stated that they related very well with other homeless persons without experiencing any problems. This view was expressed by comments such as "We live well together, for example, when there are functions on the streets we invite each other and we meet, then we go together". Others explained that they related very well with each other, though cautiously because of the principle of survival of the fittest in the sense that when one is weak or new on the streets, one will always be the target of abuse, discrimination and ridicule. The following response encapsulated this theme: "Sometimes we get along sometimes no, because some will tell you they have been long on the streets and you will be new, and we harm each other in such cases". 
All four homeless respondents who presented with symptoms of mental illness were interviewed and those who were observed seemed to enjoy a sense of belonging and felt that other homeless persons cared for and protected them. For example, one respondent indicated that "They love me, hence they don't beat me". When the homeless persons were asked about the relationship they had with other homeless mentally ill persons, they stated that they communicated and related well with the homeless persons when their mental functioning was good. This theme was captured by one respondent who indicated that "We live very well together because we are now used to him. He makes us laugh. Sometimes he is in the right senses". Another respondent emphasised the effect of their mental functioning when he commented, "Only when they inhale glue; however, when you speak to them they hear, but what they do my sister because they are mad, no man!" Lastly, one respondent stated, "We communicate well with them, even though I cannot help them because we all need help".

From the aforementioned responses it seems that even though the homeless persons with suspected mental illness relied on other homeless persons for support, care and protection, not all the homeless persons took their needs into consideration. They believed that they were on the streets to survive and their own survival needs were paramount.

\section{Theme 5: Perceptions of, and challenges associated with, service delivery to homeless and homeless mentally ill persons}

The findings indicated that there were more organisations in Hillbrow providing services to homeless people than to homeless persons with mental illness. Some of the homeless mentally ill persons accessed their mental health care services from the Mental Health Department of the Hillbrow Clinic, where one respondent reported that he and his partner had been receiving their medication for 30 years. It emerged that NGOs that offered services for homeless persons in Hillbrow only dealt specifically with homeless persons, as they indicated that they were not equipped to deal with homeless persons with mental illness. Instead, service providers referred them to appropriate organisations that were not situated in Hillbrow. Services that were provided by NGOs and Hillbrow Clinic included outreach activities, accommodation, reunification with families, assistance with grants and documentation, recreation programmes, education and training in computer literacy, awareness projects and life skills such as hygiene, referral of the homeless persons with mental illness and provision of medication and monitoring of treatment.

\section{Attitudes}

Of the four homeless respondents with suspected mental illness who were interviewed, only two were responsive when they were asked about the attitude of staff when they visited service providers for help, particularly at the clinic. They both indicated positive behaviour on the part of service providers, as expressed by comments like "They take care of me well. For example, when I was stabbed they gave me life".

Of the six homeless respondents who were interviewed, two indicated that the attitude of staff was generally positive towards them but qualified, as shown by the following 
comments: "Their attitude is ok, unless if they see that you are hurt and you are from the streets, they do not help you immediately until they are done with their clients". The other two respondents indicated that the attitude of staff was not favourable as expressed by the following verbatim responses: "When you're hurt they don't attend to you in time. At Hillbrow clinic you can die while on the queue". The other one said, "Their attitude is bad, especially when you are dirty; they tend to attend to you at a later stage". These findings were consistent with those documented by Mathiti (2006) on the notion of dirt and pollution, which has a profound impact on the attitudes of service providers towards homeless people. Similarly, Foster, Hilton, Embry, Pires and Ahmed (2014) found that negative attitudes of medical students towards homelessness and mental illness were likely to exacerbate stigma and increase social distance and substandard care. The remaining two respondents were unable to comment since they did not attend local clinics.

When the three service providers from Hillbrow Clinic were asked about their attitudes towards the homeless persons with suspected mental illness, their responses suggested that they showed empathy towards them. For example, "We treat them just like other patients; we don't discriminate against them. We don't shout at them, we don't treat them like the homeless". Another respondent said, "They are vulnerable, looking at the fact that they have no place to stay and they have mental illness. It is inhuman for them to be on the streets in their condition". Another respondent stated: "I treat them equally, just like any other patients from Hillbrow, because it is their right to be treated well".

While the researcher gained the impression that most of the service providers genuinely cared about the homeless and homeless mentally ill persons whom they served, one practitioner's negative attitude was apparent when she mentioned that both the homeless persons with mental illness and the homeless persons tended to be ungrateful, because no matter how much was done for them, they always wanted more as illustrated by the verbatim response: "Sometimes they demand things, like give us these things - they are ours, as if it is their things, rather you will be helping them out". All six service providers indicated that it was challenging working with both homeless and homeless mentally ill persons and gave reasons for these difficulties.

\section{Follow-up of clients}

The six service providers who were interviewed reported that it was difficult to conduct follow-ups with both the homeless persons with mental illness and the homeless persons in cases where they had not seen their clients for a while, as reflected in the response, "Yes we do follow-ups even though it is difficult. It is not conducive with Hillbrow being Hillbrow. It is dangerous and they are very hard to find. With the social worker she is responsible for placement. With follow-up it is us the professional nurses, who are responsible for that". Another social worker from Hillbrow Clinic stated, "If I have referred them somewhere, I make a follow-up and with some it is difficult to follow them up without a fixed address".

One respondent explained, "We used to go out on the streets to their hot spots and ask their friends. Sometimes we could find out that they are sick with HIV/AIDS. They 
cannot move anywhere and we called an ambulance for them, or to call for the hospices around and take them there. But at the moment we are not making any follow-ups, we don't know how long the Department will close this programme". (The Department of Social Development stopped the outreach project at the end of November 2011, because it had extended into other services such as the outreach project instead of focusing on homeless children, for which they were originally being funded).

A further illustrative comment was: "It is very difficult ... because they are very mobile, for example, when you start a project with them today, tomorrow it's new people coming. Also we try through our outreach project on the streets to make contact with them. There is a soup kitchen that runs five days a week and spiritual upliftment; therefore we will ask their friends during those sessions, because it is difficult for us to follow-up except with those that have been re-unified with their families".

\section{Not wanting to be in a shelter, absconding from programmes and recidivism}

Service providers reported that they were faced with clients who needed to be institutionalised in shelters but did not seem interested in that option. Reasons for avoiding institutionalisation included: being satisfied with life on the streets; the desire for independence; rejection of strict rules; not wanting the grant to be used for accommodation; and drug abuse. One service provider said, "Sometimes during the programme some they run away while you are still helping them - they just leave". The most frequent reason for dropping out of programmes was a lack of programme incentives. In terms of recidivism, one respondent commented: "Relapsing is a major challenge; you take them to shelters and the next moment you see they are back on the streets". Another respondent from the Social Work Department in Hillbrow Clinic stated her frustration: "When it comes to placement, it becomes a problem to me. For example one came to me to say he has been dismissed from a shelter and he is really sorry for his deeds. Hence he asked me as a social worker to talk to the manager to give him the last chance. I do that. After sometime he comes again with the same problem, hence in such cases there is no way forward". Drug abuse was also a big challenge for the service providers as it was linked to recidivism, that is, no matter how often they took the homeless persons for rehabilitation, they developed resistance as shown in the comment, "Also from the programmes that we link them in, they will relapse again back to drugs".

\section{Dependency issues, lack of agency and difficulties associated with taking personal responsibility}

One respondent explained: "Dependence is a problem with them, after their training they have to find their own room or apartment to rent and be responsible of themselves, but they can't. What they do is to quit the job and they know that we cannot chase them away". Another service provider commented: "Lately we had no choice but to exit them so we can take other people in the programme, because we end up being stuck with them for five years or so. We have no choice, but to get them an alternative place somewhere". 


\section{Short attention span, violence, and the need for behaviour modification}

These challenges were starkly captured in the response by one respondent who said, "It has been difficult to work with them on the day-to-day basis because their attention span is very short. They become disturbed, they cry, some they become violent you know". The social control role of social workers was discernible in the response: "It is very difficult to work with them, because first of all you have to modify their behaviour, for example, in terms of stealing, cleanliness and bringing back the culture and language, that is, how to communicate with other people".

\section{Theme 6: Strategies for overcoming homelessness}

Strategies which participants suggested for alleviating homelessness included the provision of additional accommodation, employment and clothing; involvement of civil society in volunteering to assist at homeless shelters, for example, with identity document (ID) books; skills development to equip people with the skills needed to earn a living, reunification of families; educational programmes to enhance learners' awareness of the dangers of street life and drug abuse; and the need to address causal factors such as poverty and family breakdown.

\section{FEEDBACK TO STAKEHOLDERS REGARDING THE RESEARCH}

On 12 June 2014 a workshop was held in Hillbrow for all stakeholders who had either been involved in the research study or were concerned about homelessness and mental health issues in the area as well as members of the media. The workshop was very well attended, with representatives from homeless persons, homeless persons with suspected mental illness and service providers who worked with these two groups. Among the participants were people from government organisations such as the South African Police Service, Home Affairs, Gauteng Department of Health (Mental Health) and Mental Health Directorate; local authorities e.g. Hillbrow Clinic and the Social Benefits Unit of the City of Joburg (CoJ), Displaced Persons Unit of the CoJ; and nongovernmental organisations, for example Methodist Evangelical Services (MES), Johannesburg Child Welfare, Central Gauteng Mental Health Society, Kids Haven, DeafSA, PEN, Lawyers for Human Rights and LoveLife; and educational institutions including Sparrow School, the Centre for Social Development in Africa, Wits Department of Social Work and the Wits Reproductive Health and HIV Institute (WRHI).

Following presentations on the research project, the services provided by the Displaced Persons Unit, and input from a homeless person, a highly interactive discussion was facilitated by Prof. Leila Patel. Key issues that were raised included drug abuse, reunification of homeless persons with their families, the role of the police, the role of the Department of Home Affairs regarding identification documents, psychiatric services provided for homeless persons with mental illness, and the role of occupational therapists from the Department of Health Rehabilitation. The meeting terminated with the unanimous decision to establish a forum of all concerned stakeholders under the chairmanship of the manager of the Displaced Person's Unit (CoJ). 


\section{CONCLUSIONS}

The full attendance and active participation of all participants at the workshop highlighted the importance of giving feedback to all research collaborators and community stakeholders, so that the research findings of the project could be carried forward. In line with the principles of social development, this project helped to develop community partnerships, fostered participation with a social change/transformation agenda, and contributed to the empowerment and inclusion of an oppressed and marginalised group of people (Patel, 2005). In terms of the research, despite the difficulties involved in recruiting sufficient participants as well as in administering the standardised diagnostic tool and confirming psychiatric diagnoses, the study provided a window onto the world of the homeless with suspected mental illness and their relationships with other homeless persons and service providers in the Hillbrow area. It also allowed their voices to be heard. Among the key lessons learned was the need to work closely with community psychiatric nurses in confirming diagnoses of mental illness in this complex and under-researched population.

Findings regarding the harsh and unhealthy conditions under which persons in the study lived, as well as the violence and police harassment which they experienced, suggest that their constitutional rights to security, bodily integrity and housing were being violated. Highlighting these human rights violations served an educational function and was consistent with social workers' commitment to social justice (Healy, 2014). Exposure to these conditions is also indicative of the failure of economic and social welfare policies to address their needs (Mathiti, 2006). In addition, the violence experienced by homeless persons in the study would appear to reflect the broader South African reality, where violence has been normalised as a way of resolving conflicts and asserting power over others (Sewpaul et al., 2012). Nevertheless, despite extreme vulnerability and exposure to harsh living conditions, the homeless persons were able to assert a sense of agency and control over their lives by using various survival strategies. The fact that many of them had been able to survive for long periods on the street provides testimony to their resilience. Malindi (2014:44) also highlights "resilience in the context of streetism".

The results also suggest that those homeless persons in the study with suspected mental illness were more vulnerable than other homeless persons in terms of their survival on the streets, because it was more difficult for them to obtain casual jobs and they were more dependent on their partners and other homeless persons for support and protection. Overall, the health issues of the homeless persons with suspected mental illness seemed to be worse than the general homeless group because of their vulnerability in relation to the environment.

Findings suggested that family breakdown was the most recurrent reason for homelessness in the case of both the homeless persons and those with mental illness, aggravated by poverty and unemployment. These findings need to be viewed against the backdrop of South Africa's high rates of poverty, unemployment and income inequality. Service providers endeavoured to adopt a holistic approach in their response, which is in line with views espoused by Ambrosino et al. (2008:60) that homelessness is not an isolated problem, but is inextricably interlinked with poverty, drug abuse, mental illness, 
unemployment, HIV/AIDS and family breakdown. Although service providers were genuinely motivated to help both groups of homeless persons, numerous challenges were identified, especially in following them up during outreach projects. Moreover, although South Africa has one of the best and most progressive pieces of mental health legislation, outreach services to persons with suspected mental illness were being curtailed, thereby compromising their mental wellbeing.

Strategies suggested for overcoming homelessness included involvement of the community, for example, in assisting with obtaining identification documents; support with job searches and placement; skills development to equip homeless people with the skills needed to earn a living and become self-supporting, and provision of additional accommodation - particularly for the homeless persons with mental illness who were especially vulnerable to the dangers and health hazards on the streets. Homelessness is not only an individual concern, but a public issue (Sewpaul et al., 2012). It is also particularly relevant to the profession of social work and its commitment to enhance human wellbeing, to meet basic human needs and to support vulnerable populations (Compton \& Galaway, 2005).

\section{RECOMMENDATIONS}

There is a need for the Department of Social Development to continue funding NGOs for conducting outreach projects, which play a critical role in the lives of homeless people in general and particularly homeless persons with mental illness. There is also a need for the government, together with NGOs to build more subsidised residential facilities for homeless adults and those with mental illness in Hillbrow.

Service providers, especially the NGOs that work at grassroots level, and the homeless persons with mental illness as well as homeless populations need to be actively involved in policy formulation, planning and monitoring attempts to change their situation. All stakeholders, such as the South African Police Service, social workers in different fields, government departments and civil society need to work together in order to address the problems of homelessness, ranging from prevention, early intervention, through to dealing with the manifestations of homelessness. It is imperative that the issues of alcoholism, drug abuse and its effects are included in the educational curricula of schools, and causal factors such as family disintegration, poor parenting, poverty, unemployment and other problems affecting family functioning and school attendance are addressed through family preservation and other programmes.

In view of the fact that the current study was conducted on three small non-probability samples, which precluded generalisation or transferability of the findings, there is a need to replicate the study on larger, more representative samples. There is also a need for rigorous epidemiological data on the phenomenon of homelessness - particularly in respect of homeless persons with mental illness in Johannesburg - in order to assist with policy formulation and implementation.

In conclusion, Mathiti (2006:214-215) sums up the paradox of homelessness when he states: 
"Homelessness is a paradox because it epitomizes destitution in the midst of opulence, alienation in the midst of social intimacy, and lack of a home in a home-based society ... Homelessness becomes a prism that refracts the failures of society's key sectors such as housing, welfare, education and health care”.

\section{REFERENCES}

AMBROSINO, R., AMBROSINO, R., EMERITUS, H.J. \& EMERITUS, S.G. 2008. Social work and social welfare: an introduction $\left(6^{\text {th }}\right.$ ed). Belmont, CA: Thomson Brooks/Cole.

AMERICAN PSYCHIATRIC ASSOCIATION. 2013. Diagnostic and statistical manual of mental disorders: $5^{\text {th }}$ ed. (DSMV). Arlington, Virginia: American Psychiatric Association. [Online] Available: http://en.wikipedia.org/wiki/Diag nostic_and_Statistical_Manual_ofMental_Disorders\#Uses_and_definition.

BABBIE, E. 2013. The practice of social research (International Edition) $\left(13^{\text {th }}\right.$ ed). Canada: Wadsworth Cengage Learning.

BRAUN, V. \& CLARKE, V. 2006. Using thematic analysis in Psychology. Qualitative Research in Psychology, 3(2):77-101.

CAROL, S.N., KARINA, M.E., DAVID, E.P. \& EDWARD, L.S. 2004. Are rates of psychiatric disorders in the homeless population changing? Research and Practice, 94(1):103-108.

CHRISTENSEN, R.C. 2014. Mentally ill, addicted and homeless: the need for integrated models of care for people with multiple issues. In: CLARK, C. (ed) Homelessness: prevalence, impact of social factors and mental health challenges. New York: Nova Publishers, 125-134.

COHEN, A. 2001. The search for meaning: eventfulness in the lives of homeless mentally ill persons in the Skid Row District of Los Angeles. Culture, Medicine and Psychiatry, 25:277-296.

COMPTON, B.R. \& GALAWAY, B. 2005. Social work processes. Pacific Grove, CA: Brooks/Cole.

Constitution of the Republic of South Africa. 1996. Pretoria: Government Printers.

CROSS, C., SEAGER, R.J., ERASMUS, J., WARD, C. \& O’ DONOVAN, M. 2010. Skeletons at the feast: a review of street homelessness in South Africa and other world regions. Development Southern Africa, 27(1):5-20.

Disability Rights Charter of South Africa. 2008. [Online] Available: http://www.dpsa. org.org.za/documents/disabilityrightscharter.php. [Accessed: 16/08/2010].

FOSTER, A., HILTON, S., EMBRY, F. PIRES, C. \& AHMED, A.O. 2014. Measuring attitudes towards people with mental illness and people who are homeless: Is a joint instrument needed? In: CLARK, C. (ed) Homelessness: prevalence, impact of social factors and mental health challenges. New York: Nova Publishers, 223-250. 
FREEMAN, M. 2013. Mental health in South Africa - a luta continua. [Online] Available: http://www.ru.ac.za/psychology/speechespresentations/name,83630,en.html. [Accessed: 23/01/2014].

GARVIN, C.D. 1998. Social work in contemporary society. Boston, MA: Allyn \& Bacon.

HEALY, K. 2014. Participatory action research and social work: a critical appraisal. International Social Work, 44(1):93-105.

IVANOFF, A. \& BLYTHE, B. 2011. Research ethics. In: GRINNELL, R.M. \& UNRAU, Y. (eds) Social work research and evaluation: foundations of evidencebased practice ( $9^{\text {th }}$ ed). Oxford: Oxford University Press, 71-96.

KOK, P., CROSS, C. \& ROUX, N. 2010. Towards a demographic profile of the street homeless in South Africa. Development Southern Africa, 27(1):21-37.

LEIBBRANDT, M., WOOLARD, I., FINN, A. \& ARGENT, J. 2010. Trends in South African income distribution and poverty since the fall of apartheid. Paris: Organisation for Economic Co-operation and Development (OECD Social, Employment and Migration Working Papers, no 101).

LISTER, R. 2003. Citizenship: feminist perspectives ( $2^{\text {nd }}$ ed). New York: Palgrave.

MALINDI, M.J. 2014. Exploring the roots of resilience among female street-involved children in South Africa. Journal of Psychology, 5(1):35-45.

MARKOS, P.A., BARON, H.L. \& ALLEN, D.N. 2005. A unique population: women who are homeless and mentally ill. Guidance and Counselling Spring/Summer, 20(3/4):109-116.

MATHEBULA, S. \& ROSS, E. 2013. Realizing or relinquishing rights? Homeless youth, their life on the streets and their knowledge and experience of health and social services in Hillbrow, South Africa. Social Work in Health Care, 52(5):449-466.

MATHITI, V. 2006. Homelessness. In: RATELE, K. (ed) Inter-group relations: South African perspectives. Cape Town, South Africa: Juta \& Co., 215-232.

MAY, M., PAGE, R.M. \& BRUNSDON, E. 2001. Understanding social problems: issues in social policy. Oxford: Blackwell.

McNAUGHTON, C. 2008. Transitions through homelessness: lives on the edge. New York: Palgrave Macmillan.

Mental Health Care Act 17 of 2002. Pretoria: Government Printers.

NPC. 2012. National Planning Commission. Pretoria, South Africa: The Presidency. [Online] Available: www.npconline.co.za/Executive\%20Summary-NDP\%202030\%.

O’FLAHERTY, B. 2005. City economics. Cambridge, Mass: Harvard University Press.

OLUFEMI, O. 1998. Street homelessness in Johannesburg inner-city: a preliminary survey. Environment and Urbanization, 10(2):223-234. 
PATEL, L. 2005. Social welfare \& social development in South Africa. Cape Town: Oxford University Press.

PATEL, L., HOCHFELD, T., GRAHAM, L. \& SELIPSKY, L. 2008. The implementation of the White Paper for Social Welfare in the NGO sector. Research report. Johannesburg: Centre for Social Development in Africa, University of Johannesburg.

POWER, C. \& ATTENBOROUGH, J. 2003. Up from the streets: a follow-up study of people referred to a specialist team for the homeless mentally ill: Brunner Routledge. Journal of Mental Health, 12(1):41-49.

ROSS, E. 2014. Homelessness and mental illness in South Africa. In: CLARK, C. (ed) Homelessness: prevalence, impact of social factors and mental health challenges. New York: Nova Publishers, 39-47.

SEAGER, T. \& TAMASANE, J.R. 2010. Health and well-being of the homeless in South Africa cities and towns. Development Southern Africa, 27(1):63-83.

SEWPAUL, V., OSTHUS, I.S., MHONE, C.K., SIBILO, E. \& MBHELE, S. 2012. Life on the streets of Durban: no millionaire ending. Social Work/Maatskaplike Werk, 48(3):241-357.

SHLAY, A. \& ROSSI, P. 1992. Understanding the concept of homelessness. New York: Sage Publications.

STATISTICS SOUTH AFRICA. 2014. Quarterly Labour Force Survey: Quarter 2. Pretoria: Statistics South Africa.

SUlLIVAN, G., BURNAM, A. \& KOEGEL, P. 2000. Pathways to homelessness among the mentally ill. Social Psychiatry Psychiatric Epidemiology, 35:444-450.

TIPPLE, G. \& SPEAK, S. 2009. The hidden millions: homelessness in developing countries. New York, NY: Routledge.

WARD, C.L., SEAGER, J. \& TAMASANE, T. 2007. Strategy and guidelines for children living and working in the streets. Report submitted to Department of Social Development. Pretoria, Republic of South Africa: Human Sciences Research Council.

Ms Unotida Moyo, master's graduate; Prof Leila Patel, Director of the Centre for Social Development in Africa (CSDA); Prof Eleanor Ross, Visiting Professor at the CSDA, University of Johannesburg, Johannesburg, South Africa. 